\title{
Serum FT4 / FT3 Ratio, a Predictive Biochemical Marker for Subclinical Hypothyroidism in Patients with Chronic Kidney Disease
}

\author{
Venkat Siddarth Chagamreddy ${ }^{1}$, Malligai Elancheran², Murugavel K. ${ }^{3}$ \\ ${ }^{1}$ Department of Biochemistry, Chettinad Academy of Research and Education, \\ Chengalpattu, Tamilnadu, India. ${ }^{2}$ Department of Biochemistry, Chettinad Academy of \\ Research and Education, Chengalpattu, Tamilnadu, India. ${ }^{3}$ Department of Biochemistry, \\ Chettinad Academy of Research and Education, Chengalpattu, Tamilnadu, India.
}

\section{ABSTRACT}

\section{BACKGROUND}

Subclinical hypothyroidism ( $\mathrm{ScHt}$ ) is an early stage of hypothyroidism which can progress to overt hypothyroidism and lead to adverse metabolic abnormalities. Surge in frequency of hypothyroidism is seen in chronic kidney disease (CKD) cases, including those receiving dialysis. Many studies reported the relation amid thyroid function with metabolic syndrome, though the link among the Free T3: Free T4 and ScHt is not clearly determined. We wanted to investigate the Free T3:Free T4 ratio in predicting ScHt in CKD.

\section{METHODS}

In this study, 53 known CKD subjects who have not undergone haemodialysis and 60 normal healthy subjects were included. In both study groups, creatinine and estimated glomerulus filtration rate (eGFR) are determined to evaluate the kidney function. Thyroid function parameters namely serum FT3, FT4 and TSH were measured to determine the FT3 / FT4 ratio.

\section{RESULTS}

TSH levels were significantly increased in patients with CKD not undergoing dialysis as compared to patients in the control group $(\mathrm{P}<0.034)$. Low Free T3 level $(\mathrm{P}<0.001)$ and FT3 / FT4 ratio is highly significant $(\mathrm{P}<0.001)$ in study subjects as compared to controls. Area Under the Curve (AUC) of ROC for the continuous variables of serum FT4 / FT3 ratio was 0.914 with CI: 0.832 to 0.997.

\section{CONCLUSIONS}

Individually FT3, FT4 have very little sensitivity in the diagnosis of sub clinical hypothyroidism in chronic kidney disease. FT4/FT3 ratio determination is a very useful step in diagnosing ScHt with chronic kidney disease.

\section{KEY WORDS}

Sub Clinical Hypothyroidism, FT4 / FT3 Ratio, Chronic Kidney Disease

\author{
Corresponding Author: \\ Malligai Elancheran, \\ Department of Biochemistry, \\ Chettinad Academy of Research \& \\ Education, Chengalpattu-603013, \\ Tamilnadu, India. \\ E-mail:malli.murugesan@gmail.com
}

DOI: $10.14260 / j e m d s / 2020 / 504$

How to Cite This Article:

Chagamreddy VS, Elancheran $M$, Murugavel K. Serum FT4 / FT3 ratio, a predictive biochemical marker for subclinical hypothyroidism in patients with chronic kidney disease. J Evolution Med Dent Sci 2020;9(33):2319-2323, DOI: $10.14260 /$ jemds/2020/504

Submission 17-04-2020,

Peer Review 08-07-2020,

Acceptance 15-07-2020,

Published 17-08-2020.

Copyright (C) 2020 JEMDS. This is an open access article distributed under Creative Commons Attribution License [Attribution 4.0 International (CC BY 4.0)] 


\section{BACKGROUND}

Sub Clinical Hypothyroidism (ScHt) is a clinical condition with minimal symptoms or no symptoms of hypothyroidism. ${ }^{[1]} \mathrm{ScHt}$ is defined as increased "thyroid stimulating hormone" (TSH) along with a normal "free thyroxine" (FT4) and "free triiodothyronine" (FT3) level.[2] Prevalence of ScHt was 11.3\% and is more prominent in females..[3] Women have higher range of anti TPO antibodies resulting in increase in ScHt patients. ${ }^{[4]}$ As per the "National Health and Nutrition Examination Survey (NHANES)" the yardstick to identify ScHt was elevation of TSH between 5 to $10 \mu \mathrm{IU} / \mathrm{mL}$ and with normal Free T4 without any clinical signs and symptoms. Incidence of ScHt increases with age.[5] and with greater dietary iodine intake.[4]

Prevalence of SCH has inverse relation with Glomerular filtration rate (GFR) as SCH increases slowly the GFR declines. Few studies showed the connection of ScHt and CKD which involve inflammation,[6] alteration in iodine metabolism, hormonal issues and immune system attacking thyroid. [7] CKD may be known as lower GFR of $<60 \mathrm{~mL} / \mathrm{min} / 1.73 \mathrm{~m} 2$ for $>3$ month, with presence or absence of renal damage.[8] Decreased renal blood flow due to left ventricle impairment, increase in vasoconstriction, intrarenal vasoconstriction and reduced expression of endothelium vasodilators VEGF and IGF are accountable for decreased GFR in hypothyroidism. [9-11] Epidemiological data imply that pre-dialysis cases with CKD have a higher risk of hypothyroidism.[12] ScHt is prevalent in CKD cases not getting treatment for chronic dialysis.[13] TSH is observed to increase in CKD with thyrotropin by uremic effect.[14]

Literature has been shown an increase in frequency of ScHt with CKD patients in comparison with control subjects.[15-17] ScHt has been recognized as a prediction of all causes of death in chronic dialysis subjects and as a risk factor promoting nephropathy and cardiac problems in type 2 diabetes patients.[18-19]

Many studies reported the interrelation ship of thyroid function and metabolic syndromes.[20-22] Although the link among the free T3: free $\mathrm{T} 4$ and the $\mathrm{ScHt}$ is not clear. This study aims to investigate the free T3: free T4 in prediction of ScHt in CKD subjects. Hence to determine better biochemical marker to identify the ScHt in CKD patients who are not on dialysis, which is necessary for clinician in early diagnosis, intervention and managing patients.

\section{METHODS}

A comparative cross-sectional study over 9 months' time period on patients attending Chettinad hospital \& research institute, Chennai. A total number of 60 normal healthy subjects as controls and 53 subjects suffering with CKD of varying aetiology but not undergone haemodialysis has been considered for the study after fulfilling the inclusion criterion.

Institutional Ethics Committee approval has been obtained by Chettinad Academy of Research and Education. Consent was taken from the subjects before their inclusion into the study.

\section{Inclusion Criteria}

- $\quad$ All the patients of CKD >18 years who does not require long-term dialysis (TSH > $5.5 \mathrm{mIU} / \mathrm{L}$.) The CKD was diagnosed on the basis of history and examination.

- Patients with kidney disease of more than 3 months duration.

- Abnormal urea and creatinine results.

\section{Exclusion Criteria}

- Pregnant women.

- Patients $<18$ year's.

- Previous history of usage of medication for thyroid disease; family history of thyroid.

Fasting blood sample was collected, serum Free T3, Free T4 and TSH were estimated by using chemiluminescence Immuno assay (CLIA) technique according to manufactures protocol. Serum creatinine was determined by Jaffe's Kinetic method.

Estimated GFR is calculated by using "Modification of Diet in Renal Disease" formulas to assess renal functions,

$\mathrm{eGFR}=175 \times\left(\right.$ ser creatinine $\left.^{-1.154}\right) \times\left(\right.$ age $\left.^{-0.203}\right) \times 1.212$ (if black) $\times 0.742$ (if female)

Functional sensitivities of FT3 $=0.88 \mathrm{pg} / \mathrm{mL}$, Free T4 $0.25 \mathrm{ng} / \mathrm{dL}, \mathrm{TSH}=0.015 \mathrm{uIU} / \mathrm{mL}$ and creatinine $=0.15 \mathrm{mg} / \mathrm{dL}$ was given by the manufacturer.

Reference values in our lab for Free T3=2.5-3.9 pg/mL, Free $\mathrm{T} 4=0.58-1.64 \mathrm{ng} / \mathrm{dl}, \mathrm{TSH}=0.34-4.5 \mathrm{uIU} / \mathrm{mL}$. Creatinine $=0.7-1.3 \mathrm{mg} / \mathrm{dL}$ for males and $0.6-1.0 \mathrm{mg} / \mathrm{dL}$ for females.

\section{Statistical Methods}

SPSS statistics software version 21 has been used to analyze the data. Normality of continuous variables was checked. Data shown in mean \pm SD. Continual and categorizable variable are compared with independent $\mathrm{t}$ - test. The receivers operating characteristics (ROC) curves for FT4/FT3 ratio were constructed. The area under the ROC determined by using trapezoidal rule. Independent relationship between independent variables and dependent variables were tested by canonical discriminant functional analysis. A two tailed $\mathrm{P}$ values $<0.05$ shown statistical significance.

\section{RESULTS}

Mean age has been calculated among the men and woman in control groups $38.46 \pm 8.8$ and the subjects were clinically euthyroid; and among the men and woman in case group the mean age was $57.7 \pm 13$. Mean $\pm \mathrm{SD}$ values of creatinine, estimated GFR, TSH, FT3, FT4 and FT4/FT3 ratio were shown in Table 1. TSH levels has been increased significantly in CKD patients without undergoing dialysis as compared to control groups $(\mathrm{P}<0.034)$. Free $\mathrm{T} 3$ level is less significant in $\mathrm{CKD}$ subjects when compared to control group $(\mathrm{P}<0.001)$. There is 
not much significantly different in serum Free T4 level in both the case and control groups. The serum FT4/FT3 ratio was high significance $(\mathrm{p}<0.001)$ in $\mathrm{CKD}$ subjects without undergoing dialysis as compared to controls (Figure 1). In canonical discriminant functional analysis, the presence of CKD was independently associated with subclinical hypothyroidism. The relationship of different Independent variables tested by canonical discriminant functional analysis clearly shows, serum FT3 (-0.462) value has significant role in linking ScHt and CKD. The area under ROC for the continuous variables, serum FT4/FT3 ratio was 0.914 with CI: 0.832 to 0.997 , it clearly indicates the ratio has high sensitivity and specificity, in determining the accuracy (Table 2). The results of ROC graph of our study FT4/FT3 ratio supports the association between ScHt and CKD (Figure 2).
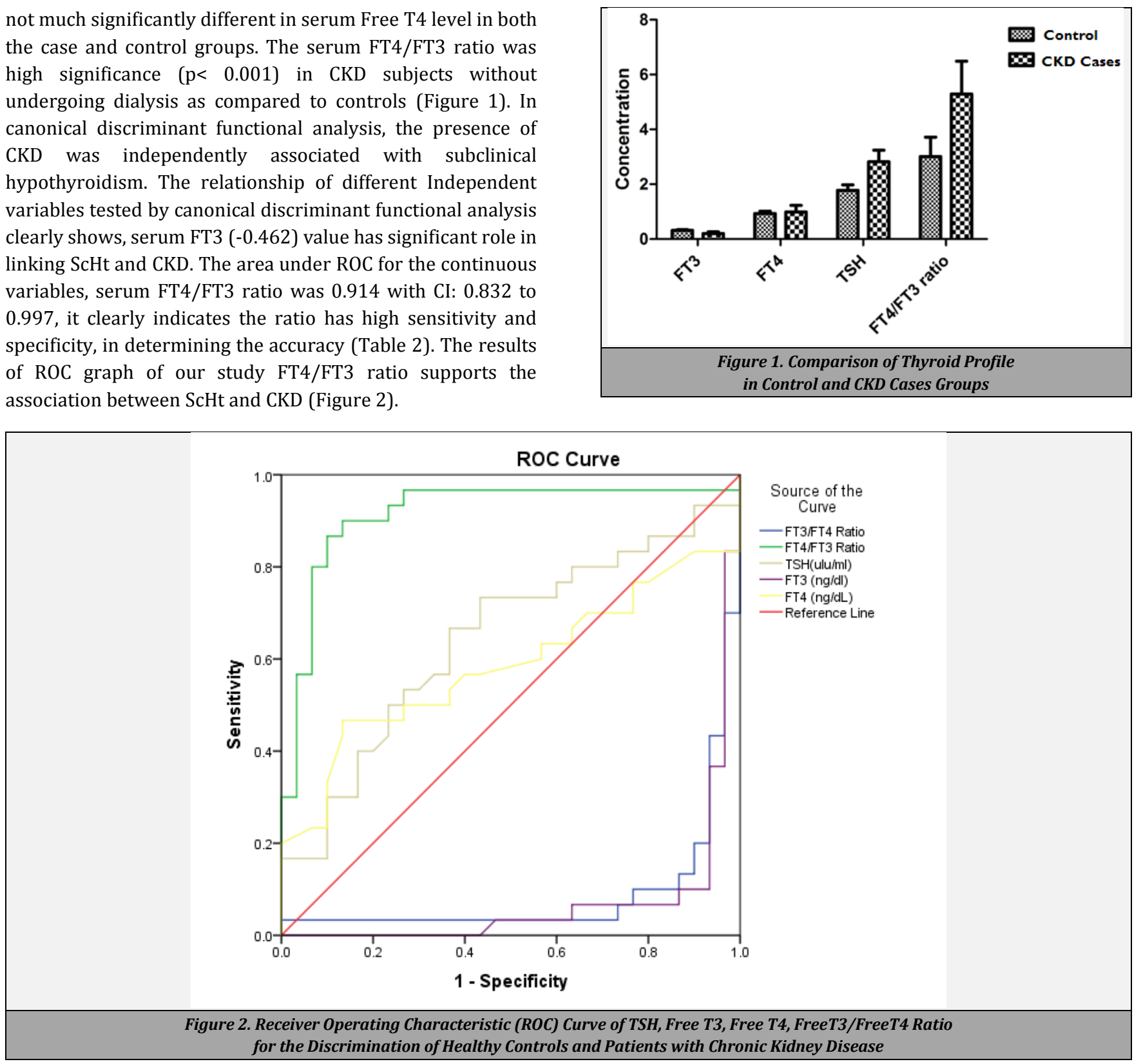

\begin{tabular}{|ccccc|}
\hline Sl. No. Parameters & $\begin{array}{c}\text { Cases } \\
\text { (Mean } \pm \text { SD) }\end{array}$ & $\begin{array}{c}\text { Controls } \\
\text { (Mean } \pm \text { SD) }\end{array}$ & P-Values \\
1 & AGE & $57.7 \pm 13.350$ & $34.33 \pm 9.444$ & $<0.001$ \\
2 & FT3 & $0.206 \pm 0.029$ & $0.318 \pm 0.16$ & $<0.001$ \\
3 & FT4 & $0.992 \pm 0.24$ & $0.93 \pm 0.088$ & NS \\
4 & TSH & $2.821 \pm 0.823$ & $1.776 \pm 0.962$ & $<0.034$ \\
5 & FT4/FT3 ratio & $5.288 \pm 2.199$ & $3.008 \pm 0.711$ & $<0.001$ \\
6 & Creatinine & $4.24 \pm 1.39$ & $0.88 \pm 0.19$ & $<0.001$ \\
7 & eGFR & $14 \pm 4.43$ & $59.6 \pm 7.85$ & $<0.001$ \\
\hline \multicolumn{5}{|c}{ Table 1. Mean and SD Values of Thyroid and Renal Profiles } \\
in Controls and Cases \\
\hline \multicolumn{5}{c}{} \\
\hline \multicolumn{5}{c}{} \\
\hline
\end{tabular}

\begin{tabular}{|c|c|c|c|c|c|}
\hline \multirow[t]{2}{*}{$\begin{array}{c}\text { Test Result } \\
\text { Variables }\end{array}$} & \multirow[t]{2}{*}{ Areas } & \multirow[t]{2}{*}{$\begin{array}{c}\text { Standard } \\
\text { Error }^{\mathbf{a}}\end{array}$} & \multirow[t]{2}{*}{$\begin{array}{l}\text { Asymptotic- } \\
\text { Significance. }\end{array}$} & \multicolumn{2}{|c|}{$\begin{array}{l}\text { Asymptotic } 95 \% \\
\text { Confidence- } \\
\text { Interval }\end{array}$} \\
\hline & & & & Lower & Upper \\
\hline FT4/FT3 Ratio & 0.914 & 0.042 & $<0.001$ & 0.832 & 0.997 \\
\hline TSH (ulu/ml) & 0.643 & 0.072 & & 0.501 & 0.785 \\
\hline FT3 (ng/dl) & 0 & & & 0.68 & 0.79 \\
\hline FT4 (ng/dL) & 0.586 & 0.077 & 0.251 & 0.435 & 0.737 \\
\hline \multicolumn{6}{|c|}{$\begin{array}{l}\text { TSH, FT3, FT } 4 \text { has minimum one tie among the +ve and -ve actual state group. } \\
\text { a. Non-parametric assumptions } \\
\text { b. Null hypothesis }\end{array}$} \\
\hline \multicolumn{6}{|c|}{ Table 2. Different Variables in the ROC Curve } \\
\hline
\end{tabular}

\section{DISCUSSION}

In the present study FT4/FT3 ratio were assessed to screen the relationship between $\mathrm{ScHt}$ and $\mathrm{CKD}$, and high odds ratio $(>1)$ justifies our hypothesis. The odds ratio for serum FT4/FT3 ratio predicted by the omnibus test for model coefficients was 4.58 and the corresponding confidence interval was 0.22 to 1.23 . The width of the interval clearly indicates larger sample size is needed for adequate precision.

Thyroid hormones may directly affect the renal function which can further lead to thyroid disorders. In the present study high prevalence of ScHt $(16 \%)$ is observed in CKD subjects. This study result is accordant with studies alike in other subjects combining kidney dysfunction with thyroid disorder. Prevalence of ScHt-primary range from $4 \%$ and $10 \%$ in normal subjects,[23-25] and from $7 \%$ and $26 \%$ in elder age group. [26-28] 
Most participants had serum TSH result in normal range (TSH value ranges $0.4-4.5 \mu \mathrm{IU} / \mathrm{ml}$ with normal Free T4 level) whereas few had ScHt $(\mathrm{TSH}>4.5 \mu \mathrm{IU} / \mathrm{ml}$ with normal Free T4 level. According to the "National Academy of Clinical Biochemistry (NACB)" recommendations the higher limit of TSH normal range in healthy population is a topic of debate suggesting $\sim 2.5 \mu \mathrm{IU} / \mathrm{mL}$, rather than $\sim 4.5 \mu \mathrm{IU} / \mathrm{mL}$, i.e due to subjects involved in that study underwent an early phase of auto-immuno thyroid disorder. This recommendation will alter the higher limit of TSH which will skew our data. In the present study to categorize $\mathrm{ScHt}$, the reference interval considered for TSH is 0.34 to $4.5 \mu \mathrm{IU} / \mathrm{mL}$. During the diagnosis of ScHt, the higher limit of TSH is very critical.

FT3 and FT4 are within the normal reference range for both controls and cases. Our results showed low Free T3 levels in patients of CKD when compared to controls; this may be due to the effect on deiodinase (convert T4 to T3) by metabolic acidosis and protein malnutrition in CKD. Since T4 conversion to $\mathrm{T} 3$ is reduced in CKD, it reflects higher side of $\mathrm{T} 4$ reference limit, but within the reference interval. TSH level in CKD patients had serum TSH levels within the reference range but only in few cases TSH level is $>4.5 \mu \mathrm{IU} / \mathrm{mL}$, with normal FT4 levels suggesting subclinical hypothyroidism. Low FT3 levels proved to be a self-reliant in prediction of mortalities in hemodialysis subjects.[29] Literature shows lower T3 level is more commonly observed, followed by ScHt.[30] In this study there is no significant difference in serum FreeT4 level in both the case and control groups. Serum FT4 levels vary from being low to normal in CKD because of an impaired protein binding of T4 in CKD.

\section{CONCLUSIONS}

Serum FT3 is always interpreted with FT4 measurement in diagnosing subclinical hypothyroidism. Individually FT3, FT4 have very little sensitivity for diagnosing ScHt in CKD. Hence, the ratio FT4 / FT3 is helpful in diagnosing ScHt in CKD. This study includes consistent methodology for collection of data on TSH, FT4 and FT3 and ScHt was diagnosed by a criterion (i.e. increased TSH with normal FT4 level) without any clinical signs and symptoms. Major limitations in our study are low sample size and the examination being limited in its ability to set up relation among $\mathrm{ScHt}$ and CKD. Also, cases and controls are not age matched; antiTPO and TBP levels were not measured. This study showed the importance of FT4 / FT3 ratio determination. Further studying it in large populations will validate the findings of this study.

Financial or Other Competing Interests: None.

\section{REFERENCES}

[1] Pearce SHS, Brabant G, Duntas LH, et al. 2013 ETA guideline: management of subclinical hypothyroidism. Eur Thyroid J 2013;2(4):215-28.

[2] Surks MI, Ortiz E, Daniels GH, et al. Subclinical thyroid disease: scientific review and guidelines for diagnosis and management. JAMA 2004;291(2):228-38.
[3] Deshmukh V, Behl A, Iyer V, et al. Prevalence, clinical and biochemical profile of subclinical hypothyroidism in normal population in Mumbai. Indian J Endocrinol Metab 2013;17(3):454-9.

[4] Shrestha U, Gautam N, Agrawal KK, et al. Iodine status among subclinical and overt hypothyroid patients by urinary iodine assay: a case-control study. Indian J Endocrinol Metab 2017;21(5):719-23.

[5] Kim YA, Park YJ. Prevalence and risk factors of subclinical thyroid disease. Endocrinol Metabol [Seoul] 2014;29(1):20-9.

[6] Zoccali C, Tripepi G, Cutrupi S, et al. Low triiodothyronine: a new facet of inflammation in end-stage renal disease. J Am Soc Nephrol 2005;16(9):2789-95.

[7] Chonchol M, Lippi G, Salvagno G, et al. Prevalence of subclinical hypothyroidism in patients with chronic kidney disease. Clin J Am Soc Nephrol 2008;3(5):1296300.

[8] Carroll LE. The stages of chronic kidney disease and the estimated glomerular filtration rate. The Journal of Lancaster General Hospital 2006;1(2):64-9.

[9] Diekman MJ, Harms MP, Endert E, et al. Endocrine factors related to changes in total peripheral vascular resistance after treatment of thyrotoxic and hypothyroid patients. Eur J Endocrinol 2001;144(4):339-46.

[10] Schmid C, Brändle M, Zwimpfer C, et al. Effect of thyroxine replacement on creatinine, insulin-like growth factor 1 , acid-labile subunit, and vascular endothelial growth factor. Clin Chem 2004;50(1):228-31.

[11] Klein I, Ojamaa K. Thyroid hormone and the cardiovascular system. N Engl J Med 2001;344(7):501-9.

[12] Chonchol M, Lippi G, Salvagno G, et al. Prevalence of subclinical hypothyroidism in patients with chronic kidney disease. Clin J Am Soc Nephrol 2008;3(5):1296300.

[13] Targher G, Chonchol M, Zoppini G, et al. Prevalence of thyroid autoimmunity and subclinical hypothyroidism in persons with chronic kidney disease not requiring chronic dialysis. Clin Chem Lab Med 2009;47(11):136771.

[14] Ramirez G, O’Neill W, Jubiz W, et al. Thyroid dysfunction in uremia: evidence for thyroid and hypophyseal abnormalities. Ann Inter Med 1976;84(6):672-6.

[15] Chang YC, Chang CH, Yeh YC, et al. Subclinical and overt hypothyroidism is associated with reduced glomerular filtration rate and proteinuria: a large cross-sectional population study. Scientific Reports 2018;8(1):2031.

[16] Srivastava S, Rajput J, Shrivastava M, et al. Correlation of thyroid hormone profile with biochemical markers of renal function in patients with undialyzed chronic kidney disease. Indian J Endocrinol Metab 2018;22(3):316-20.

[17] Zhou JB, Li HB, Zhu XR, et al. Subclinical hypothyroidism and the risk of chronic kidney disease in T2D subjects: a case-control and dose-response analysis. Medicine (Baltimore) 2017;96(15):e6519.

[18] Enia G, Panuccio V, Cutrupi S, et al. Subclinical hypothyroidism is linked to micro-inflammation and predicts death in continuous ambulatory peritoneal dialysis. Nephrol Dialy Transplant 2006;22(2):538-44.

[19] Chen HS, Wu TE, Jap TS, et al. Subclinical hypothyroidism is a risk factor for nephropathy and cardiovascular 
diseases in Type 2 diabetic patients. Diabet Med 2007;24(12):1336-44.

[20] Deshmukh V, Farishta F, Bhole M. Thyroid dysfunction in patients with metabolic syndrome: a cross-sectional, epidemiological, Pan-India study. Int J Endocrinol 2018;2018:1-6.

[21] Khatiwada S, Sah SK, Rajendra KC, et al. Thyroid dysfunction in metabolic syndrome patients and its relationship with components of metabolic syndrome. Clin Diabetes Endocrinol 2016;2:3.

[22] Chang CH, Yeh YC, Caffrey JL, et al. Metabolic syndrome is associated with an increased incidence of subclinical hypothyroidism - a cohort study. Scientific Reports 2017;7(1):6754.

[23] Canaris GJ, Manowitz NR, Mayor G, et al. The Colorado thyroid disease prevalence study. Arch Intern Med 2000;160(4):526-34.

[24] Tunbridge WM, Evered DC, Hall R, et al. The spectrum of thyroid disease in a community: the Whickham survey. Clin Endocrinol (Oxf) 1977;7(6):481-93.
[25] Schectman JM, Kallenberg GA, Shumacher RJ, et al. Yield of hypothyroidism in symptomatic primary care patients. Arch Intern Med 1989;149(4):861-4.

[26] Helfand M, Crapo LM. Screening for thyroid disease. Ann Intern Med 1990;112(11):840-9.

[27] Bagchi N, Brown TR, Parish RF. Thyroid dysfunction in adults over age 55 years. A study in an urban US community. Arch Intern Med 1990;150(4):785-7.

[28] Sawin CT, Chopra D, Azizi F, et al. The aging thyroid. Increased prevalence of elevated serum thyrotropin levels in the elderly. JAMA 1979;242(3):247-50.

[29] Zoccali C, Mallamaci F, Tripepi G, et al. Low triiodothyronine and survival in end-stage renal disease. Kidney Int 2006;70(3):523-8.

[30] Mohamedali M, Maddika SR, Vyas A, et al. Thyroid disorders and chronic kidney disease. Int J Nephrol 2014;2014:1-6. 